\title{
Mammal faunal change in the zone of the Paleogene hyperthermals ETM2 and H2
}

\author{
A. E. Chew \\ Department of Anatomy, Western University of Health Sciences, 309 E Second St., Pomona, CA 91767, USA
}

Correspondence to: A. E. Chew (achew@westernu.edu)

Received: 13 March 2015 - Published in Clim. Past Discuss.: 16 April 2015

Revised: 4 August 2015 - Accepted: 19 August 2015 - Published: 24 September 2015

\begin{abstract}
Hyperthermals" are past intervals of geologically rapid global warming that provide the opportunity to study the effects of climate change on existing faunas over thousands of years. A series of hyperthermals is known from the early Eocene $(\sim 56-54$ million years ago), including the Paleocene-Eocene Thermal Maximum (PETM) and two subsequent hyperthermals (Eocene Thermal Maximum 2 ETM2 - and H2). The later hyperthermals occurred during warming that resulted in the Early Eocene Climatic Optimum (EECO), the hottest sustained period of the Cenozoic. The PETM has been comprehensively studied in marine and terrestrial settings, but the terrestrial biotic effects of ETM2 and $\mathrm{H} 2$ are relatively unknown. Two carbon isotope excursions (CIEs) have been described in the northern part of the Bighorn Basin, WY, USA, and related to ETM2 and H2. An $\sim 80 \mathrm{~m}$ thick zone of stratigraphic section in the extraordinarily dense, well-studied terrestrial mammal fossil record along the Fifteenmile Creek (FC) in the south-central part of the basin spans the levels at which the CIEs occur in the northern Bighorn Basin. High-resolution, multiparameter paleoecological analysis of this part of the FC section reveals two episodes of significant faunal change - faunal events B1 and B-2 - characterized by significant peaks in species diversity and turnover and changes in abundance and relative body size. Faunal events B-1 and B-2 are hypothesized to be related to the CIEs in the northern part of the basin and hence to the climatic and environmental change of ETM2 and H2. In contrast with the PETM, change at faunal events B1 and B-2 is less extreme, is not driven by immigration and involves a proliferation of body sizes, although abundance shifts tend to favor smaller congeners. The response at faunal events B-1 and B-2 is distinctive in its high proportion of species losses, potentially related to heightened species
\end{abstract}

vulnerability in response to changes already underway in the lead-up to the EECO. Faunal response at faunal events B-1 and B-2 is also distinctive in that it shows high proportions of beta richness, suggestive of increased geographic dispersal related to transient increases in habitat (floral) complexity and/or precipitation or seasonality of precipitation.

\section{Introduction}

The late Paleocene and early Eocene (ca. 58-51 Myr) was an interval of global warming and massive inputs of carbon to the ocean and atmosphere (Zachos et al., 2008). Changes in temperature and carbon cycling happened on both long and short timescales. The Earth's surface warmed from the late Paleocene through the Early Eocene, culminating in the Early Eocene Climatic Optimum (EECO), the hottest sustained period of the Cenozoic ( 53-50 Myr; Zachos et al., 2001, 2008). Superimposed on this long-term change were several "hyperthermals", short-term $(<100 \mathrm{kyr})$ warming events (Cramer et al., 2003; Lourens et al., 2005). The hyperthermals are marked by large decreases in the $\delta^{13} \mathrm{C}$ composition of carbon-bearing phases in sedimentary strata, which are referred to as carbon isotope excursions (CIEs), and carbonate dissolution in deep-sea sediment. The latter suggests that the hyperthermals were related to massive inputs of reduced carbon to the ocean and atmosphere (Zachos et al., 2005). The most prominent and best known of the hyperthermals is the Paleocene-Eocene Thermal Maximum (PETM) (Zachos et al., 2008; McInerney and Wing, 2011), the onset of which now defines the base of the Eocene (Luterbacher et al., 2000). A comparison of multiple excursions in diverse carbon isotope records from the PETM indicate 
that several thousand petagrams of reduced carbon were released into the ocean-atmosphere system in $<20 \mathrm{kyr}$ (review in McInerney and Wing, 2011). This was somehow related to a $\sim 100 \mathrm{kyr}$ period of elevated global temperature $\left(5-7^{\circ} \mathrm{C}\right.$ warmer) and perturbations in Earth surface systems (Bowen et al., 2006; Gingerich, 2006; McInerney and Wing, 2011). On land, biotic response to the PETM is best known from the fossil record of the Bighorn Basin in northwestern Wyoming, which documents major intra- and intercontinental immigration, widespread temporary dwarfing, and changes in the diversity, trophic structure and physiology of floras and faunas (Clyde and Gingerich, 1998; Currano et al., 2008; Gingerich, 1989; Gingerich and Smith, 2006; Rose et al., 2012; Secord et al., 2012; Smith et al., 2009; Wing et al., 2005; Yans et al., 2006).

A major advantage of studying records across the latePaleocene-early-Eocene interval is the potential to characterize faunal responses to a range of climatic perturbations that occurred over both long and short timescales. Two additional early Eocene hyperthermals, Eocene Thermal Maximum 2 (ETM2 = H1) and H2 (Cramer et al., 2003; Lourens et al., 2005), occurred $\sim 2$ Myr after the PETM, constituting what is effectively a set of repeated natural experiments in climate change. The CIEs of ETM2 and H2 are similar but one half to one third the magnitude of the PETM CIE (Lourens et al., 2005; Nicolo et al., 2007; Stap et al., 2010). They occurred when the Earth was warmer and may have pushed high-latitude temperatures to greater extremes than the PETM (Sluijs et al., 2009). Planktonic assemblages at ETM2 and H2 were somewhat similar to those at the PETM, and the degree of response was proportionate to the magnitude of the CIEs (Foster et al., 2013; Gibbs et al., 2012; Sluijs et al., 2009; Stassen et al., 2012). However, in stark contrast with the well-studied PETM, terrestrial biotic response to ETM2 and H2 is relatively unknown. The ETM2 and H2 CIEs have been documented in the northern part of the Bighorn Basin (Abels et al., 2012) and from one other terrestrial sequence in India (Clementz et al., 2011), but neither record includes sufficient fossils to permit the testing of faunal response.

The dense, highly resolved, well-documented mammal record from the Fifteenmile Creek (FC) in the south-central part of the Bighorn Basin (Fig. 1) chronicles almost the entire early Eocene from the PETM to the beginning of the EECO (Bown et al., 1994b). The largest sample of PETM mammals has been studied and described from the FC record (Rose et al., 2012) along with other faunal events or "biohorizons", the largest of which after the PETM is Biohorizon B (Chew, 2009a; Schankler, 1980). Biohorizon B marks a major turning point in faunal diversity (Chew and Oheim, 2013) that has been correlated with paleoecological change across North America attributed to the onset of warming in the lead-up to the EECO (Woodburne et al., 2009). In the northern Bighorn Basin isotope record, the CIEs of ETM2 and $\mathrm{H} 2$ occur $\sim 60-80 \mathrm{kyr}$ after biostratigraphic events at the beginning of Biohorizon B (Abels et al., 2012), but there is no obviously correlated faunal change after Biohorizon B in the FC record (Chew, 2009a, b; Chew and Oheim, 2009). This lack was interpreted as biotic insensitivity to ETM2 and H2 (Abels et al., 2012). However, no previous analysis of the FC record achieved sufficient resolution to detect faunal perturbation on the scale of the hyperthermals ( $\sim 40 \mathrm{kyr})$. This report describes the first high-resolution, multiparameter paleoecological analysis of the exceptional FC record to characterize mammal faunal change in the zone of the ETM2 and $\mathrm{H} 2$ hyperthermals.

\section{Methods and materials}

\subsection{Collections}

The low angle of dip and wide area of exposure along the Fifteenmile Creek (FC) in the south-central part of the Bighorn Basin (Fig. 1) have permitted tying Willwood Formation (early Eocene) fossil localities by meter level to a composite stratigraphic section of $\sim 700 \mathrm{~m}$ (Bown et al., 1994b). The sampling protocol and stratigraphic section were conceived, designed and implemented with the specific goal of this level of resolution. As described by Bown and colleagues: "Recent collecting operations in the Fifteenmile Creek drainage, beginning under the University of Wyoming auspices in late 1973 and continuing with the U.S. Geological Survey and joint U.S. Geological Survey-Johns Hopkins University School of Medicine expeditions through 1992 [and thereafter], were undertaken, following the 1974 season, with the specific goal of collecting large samples of Willwood vertebrates with tight stratigraphic controls tied to fossil provenances in paleosols. Field collecting began to be consciously restricted to specific stratigraphic intervals that could be related to fossil provenances, and these are almost invariably in paleosols." The base of the FC section $(0 \mathrm{~m})$ rests on a distinctive red bed that marks the beginning of the PETM at Sand Creek Divide on the eastern edge of the study area (Rose et al., 2012). The C24r-C24n geomagnetic polarity shift has been located near the middle of the section ( $\sim 455 \mathrm{~m}$; Clyde et al., 2007). Near the top of the section $(634 \mathrm{~m})$, the ${ }^{40} \mathrm{Ar} /{ }^{39} \mathrm{Ar}$ date of a volcanic ash indicates that the upper levels are within the beginning of the EECO (Smith et al., 2004; Tsukui and Clyde, 2012). Numerical ages (56.33, 53.57 and 52.9 Myr, respectively) are assigned to these three tie points following the recent regional recalibration of Tsukui and Clyde (2012). Average sediment accumulation rates between the tie points increase from $0.165 \mathrm{~m} \times \mathrm{kyr}^{-1}$ to $0.267 \mathrm{~m} \times \mathrm{kyr}^{-1}$ above the C24r$\mathrm{C} 24 \mathrm{n}$ geomagnetic polarity shift. These rates suggest that $1 \mathrm{~m}$ of FC section thickness represents $\sim 6 \mathrm{kyr}$ in the lower levels and $\sim 4 \mathrm{kyr}$ above the $\mathrm{C} 24 \mathrm{r}-\mathrm{C} 24 \mathrm{n}$ geomagnetic polarity shift although variation in sediment accumulation rate, particularly in this part of the FC section (Bown and Kraus, 1993), severely limits the utility of such estimates. 


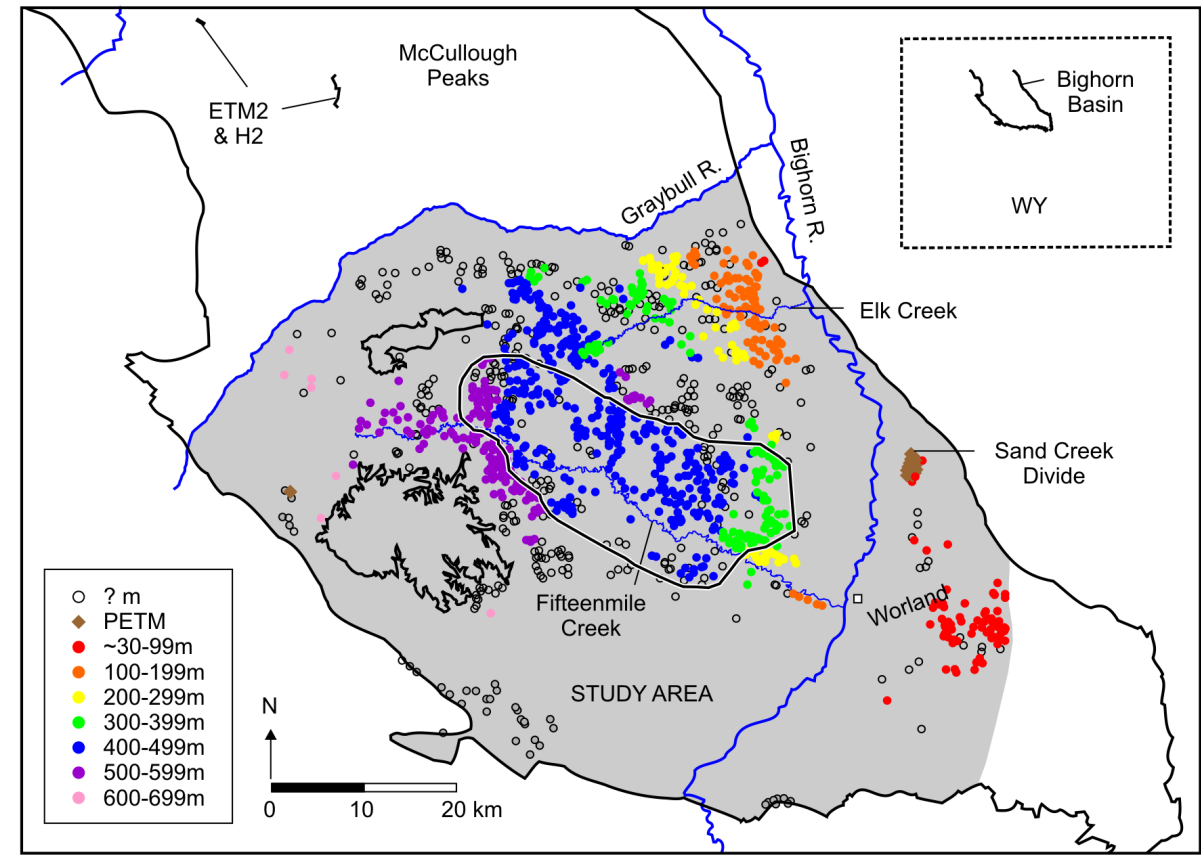

Figure 1. Fossil localities in the south-central part of the Bighorn Basin. Colored localities have been tied by meter level to the Fifteenmile Creek composite stratigraphic section of Bown et al. (1994b). Localities within the black outline in the middle of the figure span the ETM2 and H2 hyperthermal levels (290-510 m) in the Fifteenmile Creek section. Isotope sections recording the ETM2 and H2 CIEs in the McCullough Peaks are from Abels et al. (2012).

Previous analysis of paleosol carbonates was not sufficiently resolved to demonstrate the CIEs of ETM2 and H2 in the FC section (Fig. 2; Koch et al., 2003). Two CIEs attributed to ETM2 and $\mathrm{H} 2$ have been described in two isotope sections in the McCullough Peaks of the northern Bighorn Basin (Abels et al., 2012), where they are found in $60-70 \mathrm{~m}$ thick intervals of mixed geomagnetic polarity between the C24r and C24n geomagnetic zones (Fig. 2). Biostratigraphic events at the beginning of Biohorizon B are also tied to the McCullough Peaks isotope sections below the level of the ETM2 and H2 CIEs, including the last appearance of the condylarth Haplomylus speirianus and the first appearance of the artiodactyl Bunophorus etsagicus. These species cooccur at a single locality (MP 122, 5 km west of the nearest isotope section) that was traced to near the middle of $\mathrm{a} \sim 35 \mathrm{~m}$ thick gap between them in the isotope sections (Fig. 2). The C24r-C24n geomagnetic shift and the nearly simultaneous Biohorizon B biostratigraphic events are also known in the FC section. The C24r-C24n geomagnetic shift occurs at $\sim 455 \mathrm{~m}$ in two local paleomagnetic sections measured through the Dorsey and Elk creeks (Clyde et al., 2007). The latter is associated with a $30 \mathrm{~m}$ zone of mixed geomagnetic polarity. The last appearance of Haplomylus (and also of the condylarth Ectocion osbornianus originally described by Schankler (1980) as part of the suite of biostratigraphic events at the beginning of Biohorizon B) and the first appearance of Bunophorus occur at $\sim 381 \mathrm{~m}$ (this project, Fig. 2) in the FC section. The uncertainties in the stratigraphic po- sition of the $\mathrm{C} 24 \mathrm{r}-\mathrm{C} 24 \mathrm{n}$ geomagnetic shift and the biostratigraphic events at the beginning of Biohorizon B in the McCullough Peaks isotope sections, as well as pronounced variation in sediment accumulation rate around Biohorizon $\mathrm{B}$ in the FC (Bown and Kraus, 1993), preclude precise correlation between the McCullough Peaks isotope sections and the FC fossil record. However, the common occurrence of the C24r$\mathrm{C} 24 \mathrm{n}$ geomagnetic shift and the biostratigraphic events at the beginning of Biohorizon $\mathrm{B}$ in both areas indicates that the $\sim 80 \mathrm{~m}$ stretch of the FC section described here documents the interval of Bighorn Basin time in which the CIEs of the McCullough Peaks occur (Fig. 2).

All specimens included in this project were collected from 410 fossil localities spanning $290-510 \mathrm{~m}$ in the FC section. Neighboring localities along the Elk Creek (Fig. 1) have also been tied to the FC section but are excluded from this analysis (as advocated in Clyde et al., 2007) because of differences in section thickness (up to $70 \mathrm{~m}$, Bown et al., 1994b) that would compromise resolution. This exclusion results in comparatively limited sample sizes below $\sim 370 \mathrm{~m}$ (Fig. 2). More than 32,000 specimens are included in this study (Table S1 in Supplement), representing 103 lineages and species (Table S2; 68 genera, 27 families, 16 orders). Of these, $>1100$ are recently collected specimens (2004-2011 field seasons) not included in previous paleoecological analyses (Chew, 2009a, b; Chew and Oheim, 2009, 2013). Specimens are identified to species level (as in Chew, 2009a). Singleton taxa and stratigraphic outliers are excluded to avoid 


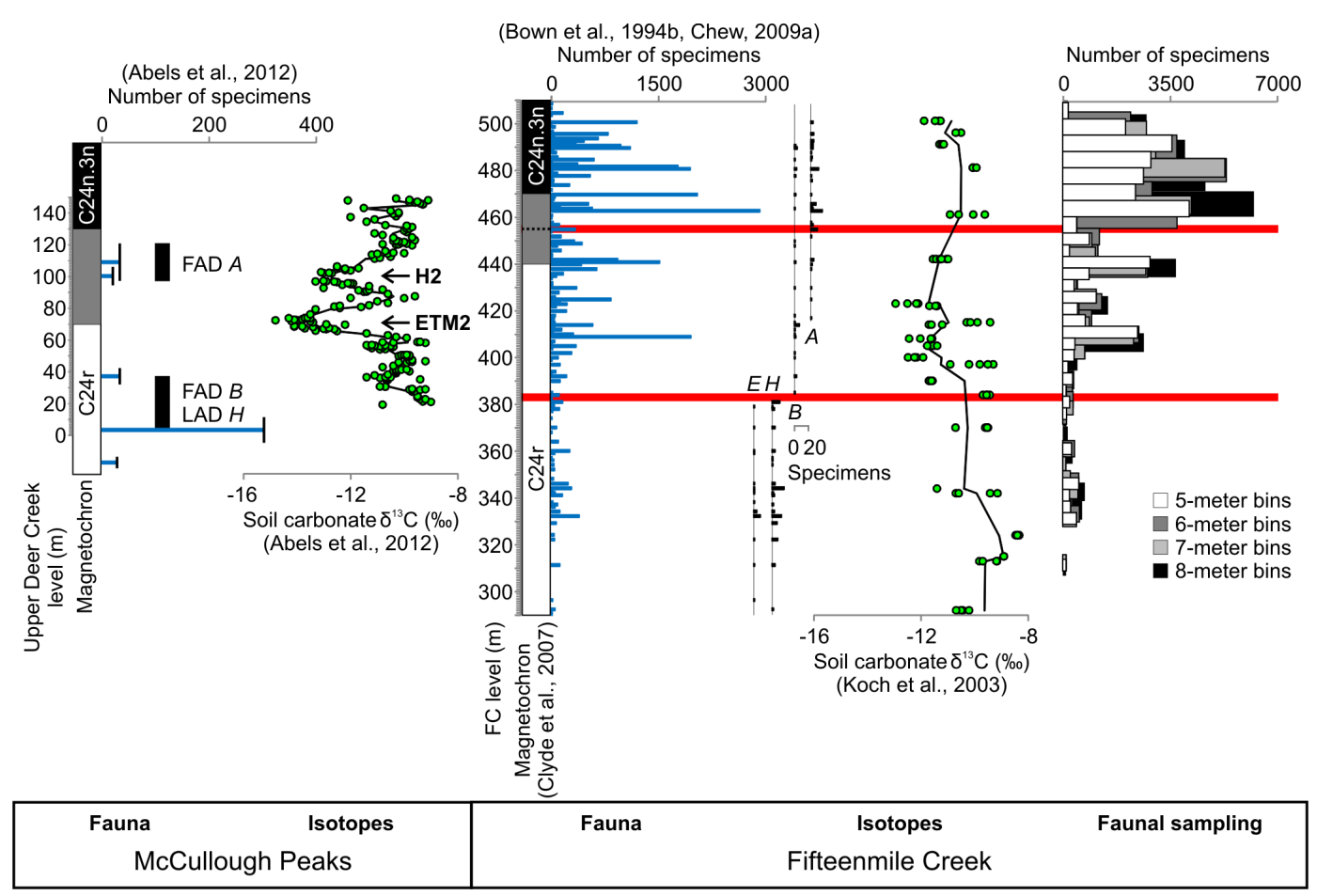

Figure 2. Available fossil samples and carbon isotope data from the northern and south-central parts of the Bighorn Basin. Both the McCullough Peaks isotope sections (Abels et al., 2012) and this part of the Fifteenmile Creek (FC) section (Bown et al., 1994b) include distinctive biostratigraphic events: the first (FAD) and last (LAD) appearances of Bunophorus etsagicus (B), Haplomylus speirianus (H), Ectocion osbornianus $(E)$ and Anacodon ursidens $(A)$. The McCullough Peaks isotope sections and this part of the FC section also include the $\mathrm{C} 24 \mathrm{r}-\mathrm{C} 24 \mathrm{n} .3 \mathrm{n}$ geomagnetic shift (gray shading indicates intervals of mixed polarity). The common occurrence of the biostratigraphic and geomagnetic events (indicated by thick, red lines for the FC section) indicates that this part of the FC section corresponds to the McCullough Peaks isotope sections. Previous isotope analysis of FC soil carbonates (Koch et al., 2003) was not sufficiently resolved to identify CIEs as in the McCullough Peaks, but those results do not preclude the possibility of CIEs in this part of the section. FC mammal fossils are binned into four series of overlapping, equal-length intervals for paleoecological analysis.

inflation of paleoecological parameters and loss of resolution. Species with single occurrences in this data set that are not excluded (Table S2) are known to have existed below $290 \mathrm{~m}$ and/or above $510 \mathrm{~m}$. A stratigraphic outlier is defined as a well-documented, clearly identifiable individual recovered $\sim 50-\sim 100 \mathrm{~m}$ outside of the stratigraphic range of the species. Seven stratigraphic outliers were identified and excluded (Anacodon ursidens - Condylarthra; Apatemys rodens - Apatotheria; Bunophorus etsagicus and Bunophorus grangeri - Artiodactyla; Lambdotherium - Perissodactyla; Pachyaena ossifraga - Mesonychia; Palaeictops bicuspis Leptictida).

\subsection{Specimen data binning}

The specimen data are binned by meter level, providing the maximum possible resolution $(\sim 4-\sim 6 \mathrm{kyr})$. At this resolution, stratigraphic gaps constitute $\sim 40 \%$ of the record and there are large disparities in sample size $(0-\sim 3000$ specimens $\mathrm{m}^{-1}$ ) and a trend of increasing sample size over time (Spearman's $\rho=0.19, p<0.05$ ), all of which complicate the calculation and interpretation of paleoecological parameters.
Although longer data bins decrease resolution, they eliminate gaps and allow extensive sample size standardization, permitting the calculation of multiple, complimentary and unbiased paleoecological parameters. Five meters is the minimum bin thickness that eliminates all gaps in the zone in which ETM2 and H2 must occur (370-455 m) in the FC section. However, each $5 \mathrm{~m}$ bin represents $\sim 30 \mathrm{kyr}$, which approaches the length of the hyperthermals under investigation and makes it impossible to construct a single binning series that divides the section appropriately to capture each event. One alternative is to combine the signals of a series of overlapping bins of different lengths (Fig. 3). Bin values are assigned to all meter levels within each bin in each series and then averaged by meter level across all bins. When multiple series are averaged in this way, the average closely approximates the original pattern (e.g., four series of all possible bins of each bin length are averaged in the binning simulation in Fig. 3). Four series of equal-time data bins are created here at 5, 6, 7 and $8 \mathrm{~m}$ bin lengths (Table S3). (To accommodate an increasing sediment accumulation rate above $\sim 455 \mathrm{~m}$, the bins in each series are lengthened accordingly: 5-7, 6-8, 7- 
10 and $8-11 \mathrm{~m})$. This results in a total of 26 separate binning series, which is prohibitive for the calculation of all parameters. An exhaustive search to minimize gaps and maximize bin sample sizes identified an "optimal" series at each bin length to be used in the calculation of averaged, standardized parameters. Basing the parameter averages on this subset of optimal binning series slightly reduces the accuracy of the resultant curve (equivalent to the dashed line in Fig. 3). To test the accuracy of the binning protocol, the binned, averaged parameters are compared with (sample size biased) parameters calculated from specimen data binned by meter level where possible.

Each binning series provides species abundance data and the levels of species' first and last appearances within the stratigraphic range of this data set. An algorithm is used to standardize these data by randomly sampling (without replacement) each bin to a sample size of 100 specimens. This process is repeated a specified number of times. From each run through each binning series the algorithm tabulates species' first and last appearances and the total number of range-through species per bin (assumed present if found in bins above and below a gap). The algorithm is modified from a previous version (Chew, 2009a) to discount first and last appearances that occur outside of the stratigraphic range of this data set to reduce edge effects (Foote, 2000). From each set of repeated runs for each binning series, average first and last appearance and range-through species data are produced per bin, as well as the average number of times each species occurs in each bin. The latter are multiplied by the species' relative abundance in each bin to create standardized proportional relative abundances.

\subsection{Paleoecological parameters}

To characterize the FC mammal fauna, fundamental concepts in paleoecology are parameterized, including diversity (the interplay between species richness and the evenness of abundance distributions) and turnover (compositional change through evolution and migration). These are complex, multifactorial concepts and diversity in particular is often oversimplified (Magurran, 2004). Here, diversity is represented as variation in the average number of species in assemblages (alpha richness), the differentiation in richness between assemblages (beta richness), the equality of species relative abundances (evenness) and the commonness of one or a few species (dominance). Turnover is characterized by rates of species' first and last appearances. Most of the parameters are dependent on sample size and are standardized or calculated from the standardized appearances and relative abundances provided by the subsampled treatment of the binned data.
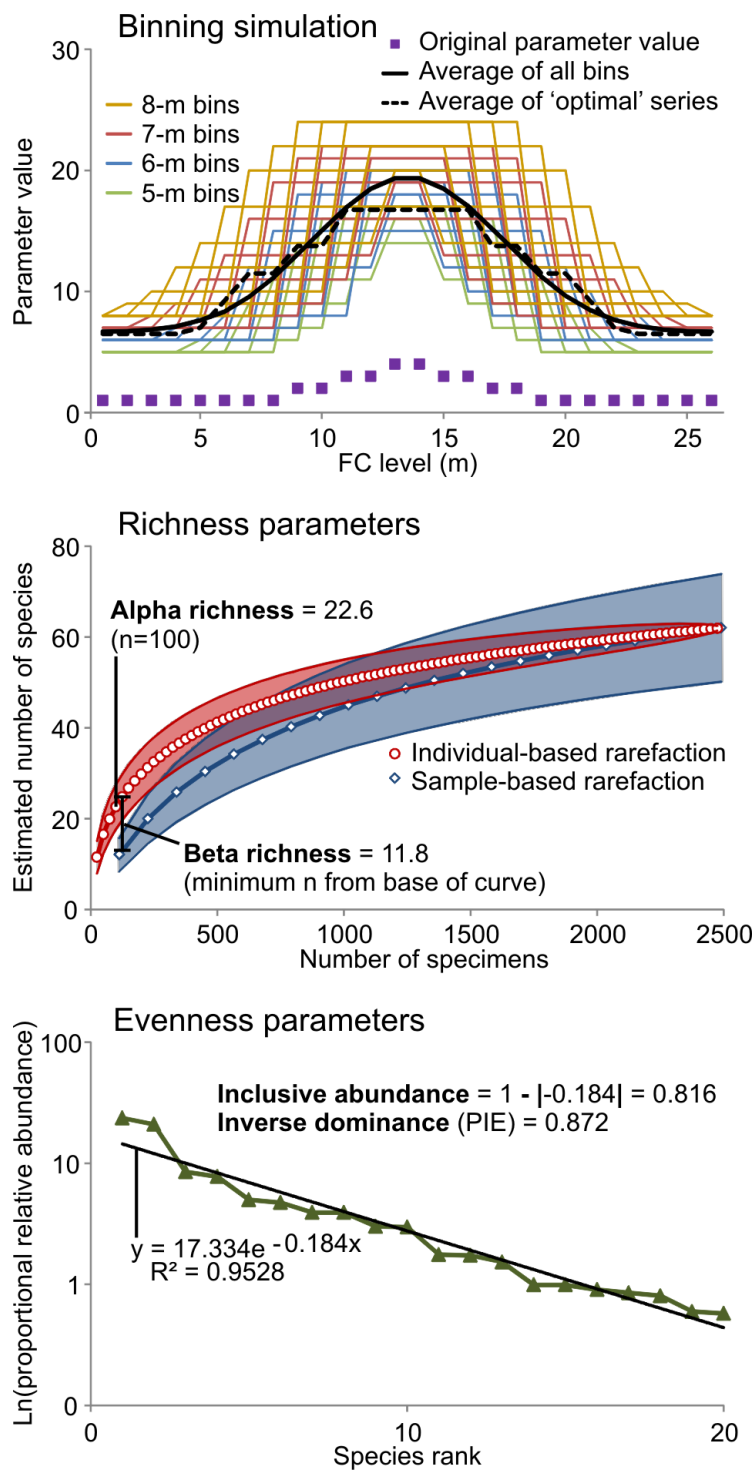

Figure 3. Illustration of the methods. The binning simulation illustrates a series of all possible bins at 5, 6, 7 and $8 \mathrm{~m}$ thickness (thin lines) created for a hypothetical parameter distribution (purple squares) with a $10 \mathrm{~m}$ peak. Parameter values are assigned to all meter levels within each bin and averaged by meter level across all bins (solid black line). Because calculation of parameters for all possible binning series is prohibitive, this project uses the average of the optimal binning series (least number of gaps and maximum sample sizes) at each thickness (dashed black line). The richness and evenness parameters are calculated from a representative binned sample (407-413 m). Alpha richness is the individual-based rarefaction estimate of the number of species in a sample of 100 specimens. Beta richness is the difference between the individual- and sample-based rarefaction curves at the base of the sample-based rarefaction curve. Inclusive abundance is the reciprocal of the absolute value of the slope of the exponential trend line of the rank-abundance curve. Inverse dominance is the probability of interspecific encounter index. 


\subsubsection{Richness}

Richness is the number of species present in a sample and is highly dependent on sample size. Where samples allow ( $>100$ specimens, continuously distributed), rarefaction is used to produce standardized estimates of richness (Colwell, 2013; Holland, 2003). Alpha (average, within-sample) richness is estimated using conventional, individual-based rarefaction (IR; Fig. 3), which plots the number of species found through the accumulation of individuals (Hurlburt, 1971; Sanders, 1968). Point estimates of alpha richness at a sample size of 100 specimens are directly comparable between samples. To estimate beta (differentiation between sample) richness, sample-based rarefaction (SR; Fig. 3) is used, which plots the number of species that are found through the accumulation of samples (Chiarucci et al., 2008; Colwell et al., 2004; Gotelli and Colwell, 2001). SR is dependent upon the spatial distribution of specimens. In the presence of distributional heterogeneity, SR richness estimates are lower than IR richness estimates, as IR assumes a random distribution of individuals and produces a curve of maximal, theoretical richness (Colwell et al., 2004; Foote, 1992; Gotelli and Colwell, 2001; Olszewski, 2004). The difference between IR and SR curves reflects beta richness (Crist and Veech, 2006; Gotelli and Colwell, 2001; Olszewski, 2004) and is largest near the base of the SR curve (Fig. 3). Comparable IR and SR point richness estimates from the base of each SR curve are used to estimate beta richness (as in Chew and Oheim, 2013). Gamma (total landscape) richness is the sum of alpha and beta richness.

\subsubsection{Evenness}

Aspects of evenness are independent of sample size, but evenness is difficult to characterize (Magurran, 2004). Two indices are used here, both calculated from standardized proportional relative abundances. The first is the well-known probability of interspecific encounter (PIE) index (Hurlburt, 1971), which is the inverse of Simpson's dominance index standardized for finite collection size.

$\mathrm{PIE}=1-\left[{ }_{i}\left(n_{i}-1\right) / N(N--1)\right]$,

where $n_{i}$ is the number of specimens of species $i$ and $N$ is the total number of specimens in a sample. Though widely employed as a descriptor of the "evenness" of species abundance distributions, PIE is strongly correlated with the proportional relative abundance of the two most common species in these data (mainly equid and hyopsodontid species; Spearman's $\rho=-0.49$ to $-0.84, p=0.00)$. To avoid confusion, it is referred to here as an index of "inverse dominance". The second index is a modification of rankabundance analysis (Fig. 3), in which species are ranked from most to least abundant and their natural-log-transformed relative abundances are plotted against ranks (Magurran, 2004). Rank-abundance curves provide a visual representation of an abundance distribution that is shaped by the majority of the species present in a sample. The slopes of exponential trend lines fitted to the curves are directly comparable between samples (Fig. 3; as in Caron and Jackson, 2008). The fit of the trend lines for these data is high $\left(R^{2}>0.75\right)$ and the slopes of the trend lines are shallow and negative $(<-0.1)$. The reciprocal of the absolute value of the slopes is used to transform them into an index of "inclusive abundance". The two indices have values between 0 and 1 . Higher values of inverse dominance indicate higher evenness through decreased dominance of the sample by a few taxa. Higher values of inclusive abundance indicate higher evenness through a more equal distribution of the abundances of the majority of the species in the sample. The two indices are summed as an index of evenness.

\subsubsection{Turnover}

Rates of species' first, $F$, and last, $L$, appearances are highly dependent on sample size. Standardized, instantaneous pertaxon rates are calculated for series of consecutive samples of equal time (as in Alroy, 2000; Chew, 2009a; Foote, 2000).

$F=-\ln [(\mathrm{RS}-\mathrm{FA}-\mathrm{LA}) /(\mathrm{RS}-\mathrm{LA})]$

and

$L=-\ln [(\mathrm{RS}-\mathrm{FA}-\mathrm{LA}) /(\mathrm{RS}-\mathrm{FA})]$,

where FA is the number of first appearances, LA is the number of last appearances and RS is the range-through richness of each sample. Turnover is the sum of these rates.

\section{Results}

The parameters calculated from $1 \mathrm{~m}$ bins and averaged from the coarser binning series correspond closely (Fig. 4). Three overlapping peaks occur in both sets of parameters (370$394 \mathrm{~m}, 405-417 \mathrm{~m}$ and 435-448 m), significantly refining previous work at a coarser resolution ( $20 \mathrm{~m}$ thick intervals), in which a single, $40 \mathrm{~m}$ thick interval $(370-410 \mathrm{~m})$ of biotic change was identified in this part of the FC section (Chew, 2009a). This analysis demonstrates two distinct events within that $40 \mathrm{~m}$ zone, separated by $\sim 10 \mathrm{~m}$ of pre-event parameter values. The lowest peak is the longest and is distinguished by high turnover driven by many species' first appearances (Fig. 4). It contains the distinctive biostratigraphic events conventionally referred to Biohorizon B (Bown et al., 1994b; Chew, 2009a; Schankler, 1980), including the last appearances of the condylarth genera Haplomylus and Ectocion and the first appearance of the artiodactyl Bunophorus (Table 1). The middle and upper peaks are comparatively short and are distinguished by increases in diversity driven by beta richness (Fig. 4). The middle peak was previously thought to be part of Biohorizon B and the upper peak falls within a longer interval of previously recognized, heightened and 

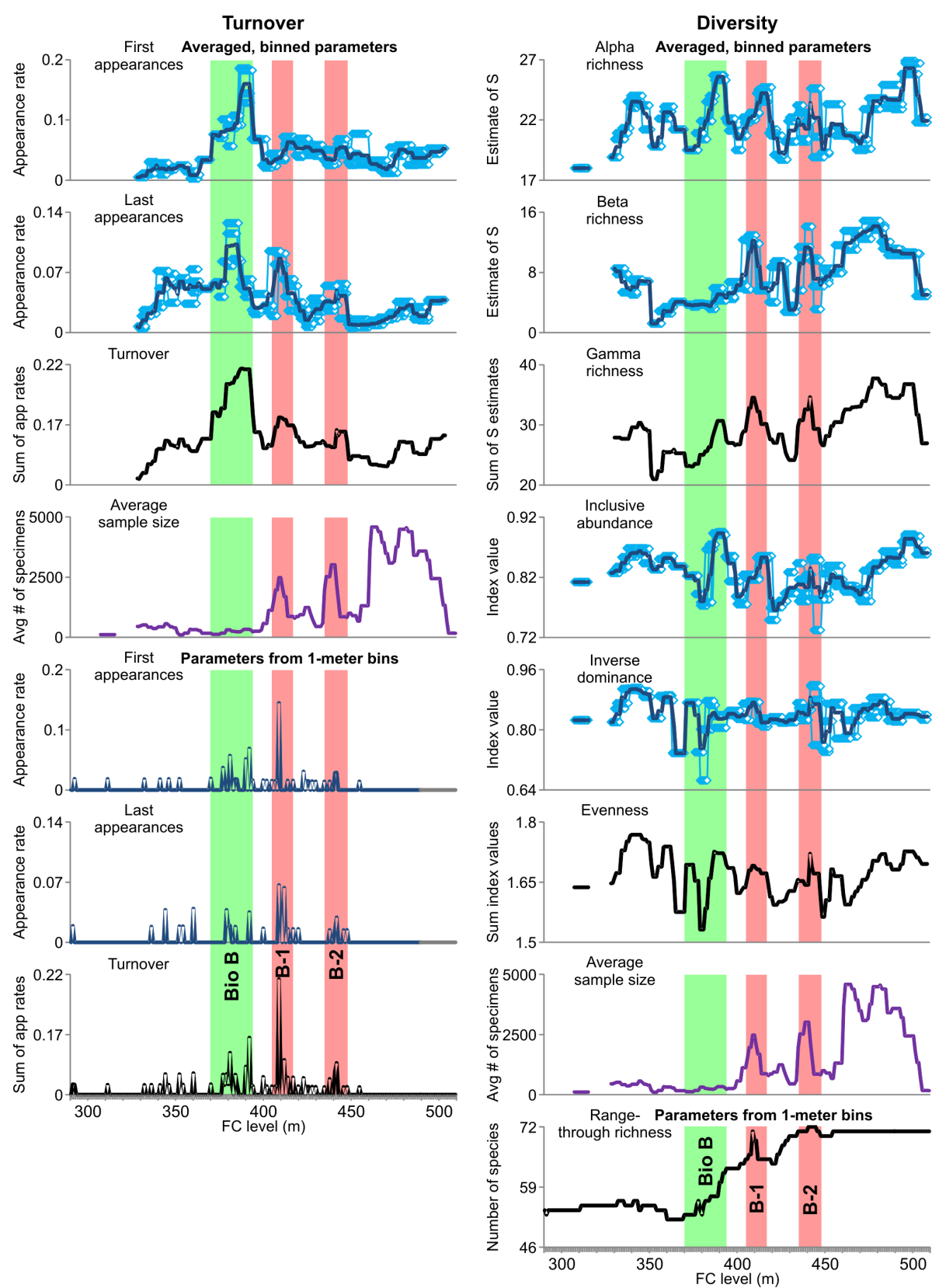

Figure 4. Paleoecological parameters calculated for the FC fossil mammal fauna. The individual turnover, richness and evenness parameters averaged from the optimal 5, 6, 7, and $8 \mathrm{~m}$ thick binning series (blue lines) and individual bin values (diamonds) are shown along with summative turnover, richness and evenness parameters (black lines). The averaged, binned parameters are compared with the original (prior to standardization) average, binned sample sizes (purple lines) to demonstrate little likelihood of lingering sample size bias. The averaged, binned parameters are also compared with turnover and range-through richness $(S)$ parameters (sample size biased) calculated from the data binned by meter level to demonstrate the congruence of parameter peaks.

fluctuant diversity after Biohorizon B (Chew, 2009a; Chew and Oheim, 2013; Schankler, 1980). The middle and upper peaks are referred to here as faunal events B-1 and B-2, given their close association with Biohorizon B. Although faunal event B-1 encompasses more species' first and last appearances than Biohorizon B (Table 1), appearance rates (Fig. 4) demonstrate that turnover is less pronounced at the faunal events in relation to higher standing richness, and neither event appears to warrant the term "biohorizon".

Focusing on the averaged parameters from the binned data, the turnover and diversity changes at faunal events B1 and B-2 are highly significant. Two-sample KolmogorovSmirnov tests of the evenness and turnover parameters indicate that the parameter distributions above (and excluding) 
Table 1. First and last appearances of species at Biohorizon B and faunal events B-1 and B-2. Paired species represent segments of what are thought to be individual lineages. Taxa in parentheses did not have first or last appearances within the significant intervals but are probably related to the event. Bold-faced taxa indicate the appearance or disappearance of a genus.

\begin{tabular}{|c|c|}
\hline \multicolumn{2}{|c|}{ Biohorizon B } \\
\hline Disappearances - 379-392 m & Appearances - 370-394 m \\
\hline Ectocion, Haplomylus, Plagiomene & $\begin{array}{l}\text { Ambloctonus, Anemorhysis pattersoni, Bunophorus grangeri, } \\
\text { Bunophorus etsagicus, Cantius new sp., Chriacus gallinae, } \\
\text { Copelemur, Homogalax sp., Hyopsodus minor, Minippus, } \\
\text { Palaeictops, Systemodon, Vulpavus australis }\end{array}$ \\
\hline Cantius trigonodus - & Cantius abditus \\
\hline Hyopsodus wortmani - & Hyopsodus latidens \\
\hline Prototomus martis - & Tritemnodon gigantea \\
\hline Prototomus sp. - & Prototomus secundarius \\
\hline \multicolumn{2}{|c|}{ Faunal event B-1 } \\
\hline Disappearances - 409-417 m & Appearances - 405-417 m \\
\hline $\begin{array}{l}\text { Cardiolophus, Dissacus sp., Miacis exiguus, Microparamys } \\
\text { scopaiodon, Pachyaena ossifraga, Pseudotetonius, Viverravus } \\
\text { politus, Viverravus rosei } \\
\text { Apheliscus insidiosus - } \\
\text { Arenahippus pernix - } \\
\text { Diacodexis metsiacus - } \\
\text { Didymictis protenus - } \\
\text { (Galecyon mordax } 357 \mathrm{~m})- \\
\text { (Thryptacodon antiquus } 360 \mathrm{~m})-\end{array}$ & $\begin{array}{l}\text { Anacodon, Apatemys rodens, Hyopsodus powellianus, } \\
\text { Oxyaena forcipata, Phenacodus sp., Prolimnocyon sp., } \\
\text { Steinius, Uintacyon new sp. 1, Xenicohippus grangeri } \\
\text { (Apheliscus sp. } 423 \mathrm{~m} \text { ) } \\
\text { Eohippus angustidens } \\
\text { Diacodexis secans } \\
\text { Didymictis lysitensis } \\
\text { Galecyon sp. } \\
\text { Thryptacodon loisi }\end{array}$ \\
\hline \multicolumn{2}{|c|}{ Faunal event B-2 } \\
\hline Disappearances - 435-448 m & Appearances - 438-442 m \\
\hline Oxyaena intermedia, Prolimnocyon sp., Uintacyon rudis & Absarokius abbotti, Hexacodus, Phenacolemur willwoodensis \\
\hline Esthonyx spatularius - & Esthonyx sp. \\
\hline Arenahippus aemulor - & Protorohippus venticolum \\
\hline Prolimnocyon atavus - & Prolimnocyon antiquus \\
\hline
\end{tabular}

Biohorizon B vary significantly from their distributions in the $\sim 40 \mathrm{~m}$ prior to Biohorizon B (Table S4; KolmogorovSmirnov $p$ values $<0.000$ ). Mann-Kendal tests indicate significant trends in a number of the parameters, but the $a b-$ solute value of all trend slopes is $<0.001$ (Table S4), and it is unlikely that these trends influence the significance of the differences. Alpha richness is not significantly different after Biohorizon B compared with before, but the peaks in gamma richness at ETM2 and $\mathrm{H} 2$ are driven by beta richness (Fig. 4), which is significantly different (Table S4; Kolmogorov-Smirnov $p=0.002$ ). Mann-Kendal tests indicate significant and opposing trends from before to after Biohorizon B in beta richness, but these also have absolute slope values of $\sim 0.01$ (Table $S 4$ ) that are unlikely to greatly influence the significance of the differences in parameter distribution.

Only the richness parameters are significantly correlated with the averaged, binned sampling distribution, which might suggest lingering sample size bias in spite of the extensive standardization instituted here. The correlation between alpha richness and the averaged, binned sampling distribution is weak (Spearman's $\rho=0.28, p=0.00$ ), with many of the peaks in alpha richness (e.g., Biohorizon B) corresponding to lows in sampling. The correlation between beta richness and the original sampling distribution is strong (Spearman's $\rho=0.91, p=0.00$ ), but previous work (Chew and Oheim, 2013) demonstrated an increase in beta richness in this part of the FC section in samples that were rigorously standardized for both sampling and area variation, to the latter of which beta richness is particularly susceptible. Combined with the lack of correlation with the other parameters and weak correlation with alpha richness, this suggests that the strong correlation between beta richness and the averaged, binned sampling distribution reflects independent trends including an increase in preservation (sampling) and differentiation across the landscape (beta richness). Finally, apart from inclusive abundance, the averaged parameters are significantly correlated with average carbon isotope value (Spearman's $\rho=0.35-0.83, p \leq 0.04$ ) when the McCullough Peaks isotope record (Abels et al., 2012) is independently correlated with the FC section using the stratigraphic ranges of faunal 
events B-1 and B-2 as determined from species range end points.

Ten families constitute $>90 \%$ of the Willwood fauna and are sufficiently common to assess proportional relative abundance and body size trends across the part of the FC section under investigation here (Fig. 5). Abundance changes are most pronounced at Biohorizon B but many appear to play out across the subsequent faunal events B-1 and B-2. There is a proliferation of body sizes at and above Biohorizon B, but abundance changes appear to favor smaller relative sizes. In two of the four most common families (Hyopsodontidae and Adapidae), closely related species that are smaller than the common lineage representing each family appear in high abundance across Biohorizon B and faunal events B-1 and B2 . This includes the largest abundance change in this part of the FC section, in which the small hyopsodontid Hyopsodus minor almost completely displaces the common hyopsodontid lineage between Biohorizon B and faunal event B-2 (proportional relative abundance of $30-40 \%$ decreases to $\sim 7 \%$ after faunal event B-2). In three of the remaining families (Phenacodontidae, Isectolophidae, Viverravidae), a common, large species disappears or markedly decreases in abundance across Biohorizon B and faunal events B-1 and B-2. In two other families (Esthonychidae, Oxyaenidae), a comparatively large lineage increases in abundance after faunal event B-2. Finally, the microsyopids experience a dramatic decrease in abundance at Biohorizon B that is maintained to some extent across faunal events B-1 and B-2, which is probably associated with a temporary reduction in body mass (Silcox et al., 2014).

\section{Discussion}

High-resolution, multiparameter paleoecological analysis of the superb FC fossil record from the south-central part of the Bighorn Basin demonstrates two previously unrecognized intervals of change, faunal events B-1 and B-2. These events immediately follow Biohorizon B but differ notably from it, suggesting different underlying causes and that their differentiation from Biohorizon B is warranted. Faunal events B-1 and B-2 may be related to the CIEs identified in the McCullough Peaks and thus represent a response to the ETM2 and H2 hyperthermals. Faunal events B-1 and B-2 occur above the distinctive biostratigraphic events of Biohorizon $\mathrm{B}$ and in close proximity to the $\mathrm{C} 24 \mathrm{r}-\mathrm{C} 24 \mathrm{n}$ geomagnetic shift, as do the CIEs in the McCullough Peaks (Abels et al., 2012). Faunal events B-1 and B-2 are similar in all aspects of faunal change described here. The simplest explanation for their similarity is a comparable trigger, and ETM2 and $\mathrm{H} 2$ are akin (Abels et al., 2012; Sexton et al., 2011; Stap et al., 2010). Change at faunal events B-1 and B-2 is superficially similar to that described at the only other well-known early Eocene hyperthermal, the PETM (Gingerich, 1989; Rose et al., 2012; Secord et al., 2012), including increases in diversity and

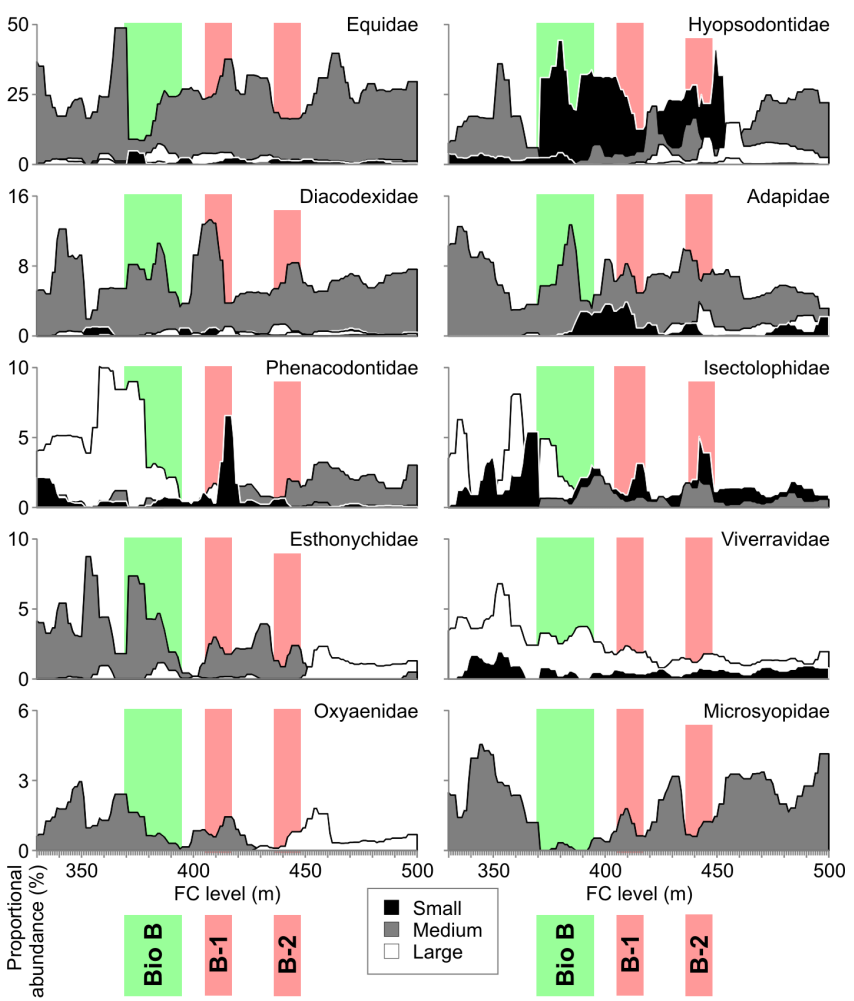

Figure 5. Changes in proportional relative abundance of species and comparative body sizes in the 10 most abundant families in the FC fossil mammal fauna. Equidae: small - Minippus index; medium - Arenahippus pernix lineage, Xenicohippus grangeri; large Arenahippus aemulor lineage, Xenicohippus craspedotum. Hyopsodontidae: small - Haplomylus speirianus, Hyopsodus minor; medium - Hyopsodus wortmani lineage; large - Hyopsodus lysitensis, Hyopsodus powellianus. Diacodexidae: small - Diacodexis gracilis; medium - Diacodexis metsiacus lineage; large - Diacodexis robustus, Bunophorus grangeri, Bunophorus etsagicus, Hexacodus sp. Adapidae: small - Copelemur feretutus; medium - Cantius trigonodus lineage; large - Cantius new sp. Phenacodontidae - small: Copecion brachypternus, Ectocion osbornianus; medium Phenacodus vortmani, Phenacodus sp.; large - Phenacodus intermedius, Phenacodus trilobatus. Isectolophidae: small - Cardiolophus radinskyi, Homogalax sp.; medium - Systemodon tapirinus; large - Homogalax protapirinus. Esthonychidae: medium - Esthonyx bisulcatus, Esthonyx spatularius lineage; large - Esthonyx acutidens. Viverravidae: small - Viverravus acutus; large - Didymictis protenus lineage. Oxyaenidae: medium - Oxyaena intermedia; large - Oxyaena forcipata. Microsyopidae: Microsyops angustidens lineage.

turnover and a general shift towards smaller body size. In addition, the increases in (alpha) richness and turnover are less pronounced at faunal events B-1 and B-2 than at the PETM (Table 2), which is also the case in marine plankton across the hyperthermals (Foster et al., 2013; Gibbs et al., 2012; Stassen et al., 2012) and conforms with the expectation that ETM2 and $\mathrm{H} 2$ were smaller events. For discussion purposes, it is hypothesized here that there is a relationship between 
the McCullough Peaks CIEs and ETM2 and H2, on the one hand, and faunal events B-1 and B-2 on the other. A critical test of this hypothesis requires directly related isotope data, which are presently unavailable.

\subsection{Comparison with the PETM}

Turnover and changes in body size at the PETM are dramatic compared with faunal events B-1 and B-2 (Table 2). Pronounced turnover at the PETM was recognized long before the hyperthermal was known by the placement of the first major boundary (Clarkforkian-Wasatchian) in the North American Land Mammal Age sequence (Wood, 1941). Nearly half of the Bighorn Basin mammal genera and $80 \%$ of the species that existed during the PETM are new (Rose et al., 2012; Woodburne et al., 2009). This turnover was fueled by immigration; up to $\sim 40 \%$ of new genera at the PETM were immigrants (Rose et al., 2012; Woodburne et al., 2009) from the southern part of the continent (Burger, 2012; Gingerich, 2001) and from the Holarctic continents via northern land bridges (Bowen et al., 2002; Gingerich, 2006; Rose et al., 2011). In comparison, $<10 \%$ of genera at faunal events B-1 and B-2 are new (Table 2) and none of these are documented immigrants (Woodburne et al., 2009). Decreases in body size at the PETM are widespread (e.g., Smith et al., 2009), including $\sim 40 \%$ of all mammal genera (Secord et al., 2012). These decreases occurred through temporary dwarfing of lineages and species via metabolic effects or through the immigration of closely related, smaller species (Burger, 2012; Clyde and Gingerich, 1998; Gingerich, 2001; Secord et al., 2012; Smith et al., 2009). In comparison, $<20 \%$ of genera at faunal events B-1 and B-2 experience decreases in body size and there is preliminary evidence of dwarfing in only a few primate lineages (D'Ambrosia et al., 2014; Silcox et al., 2014). Smaller body sizes at faunal events B-1 and B-2 are primarily the result of abundance shifts and appearance events that are not related to significant migration, although they could represent range shifts of smaller regional congeners (Fig. 4; see also Bown et al., 1994a). There are no genera that increase in body size at the PETM, whereas this proportion is $\geq 20 \%$ at faunal events B-1 and B-2 (Table 2).

Specific conditions of the hyperthermals may account for these differences. In the Bighorn Basin, mean annual temperature (MAT) increased by $5-10^{\circ} \mathrm{C}$ in $\leq 10 \mathrm{kyr}$ at the beginning of the PETM (Fricke and Wing, 2004; Koch et al., 2003; Secord et al., 2010; Wing et al., 2005). There are no MAT estimates for the predicted levels of ETM2 and H2 in the Bighorn Basin, but the proportionality of warming and CIE magnitude in regional comparisons (Abels et al., 2012) suggests that MAT increased at about one half to one third the rate of PETM warming $\left(3-6\right.$ and $2-5^{\circ} \mathrm{C}$, respectively, in $\sim 10 \mathrm{kyr}$, but see Snell et al., 2014). Continental precipitation varied regionally at the PETM (Collinson et al., 2003; Foreman et al., 2012; Samanta et al., 2013; VanDeVelde et al., 2013), but in the Bighorn Basin there was notable drying, related to a $\sim 40 \%$ decrease in mean annual precipitation (Kraus et al., 2013; Kraus and Riggins, 2007; Wing et al., 2005). In contrast, the distinct lithology of the ETM2 and H2 levels in the McCullough Peaks record, including thick purple paleosols, increased channel sandstones and mud-filled scours (Abels et al., 2012), are suggestive of moist conditions (as in Foreman et al., 2012; Kraus et al., 2013; Kraus and Riggins, 2007) and there is no evidence of drying in floras at this time (Wilf, 2000; Wing et al., 2000). Rapid range shifts and dwarfing have been linked with both moisture limitation and high rates of warming in modern terrestrial organisms (Chen et al., 2011; Foden et al., 2007; Sheridan and Bickford, 2011). It may be the combination of rapid warming and significant drying at the PETM that led to disproportionate immigration and dwarfing compared with faunal events B-1 and B-2.

\subsection{Characteristics of faunal events B-1 and B-2}

Faunal events B-1 and B-2 are set in the context of pronounced climatic, environmental and faunal change attributed to warming in the run-up to the EECO (Chew, 2009a; Woodburne et al., 2009). Leaf margin analysis of scattered floras (Wing et al., 1991) and isotope ratios of paleosol hematites (Bao et al., 1999; Wing et al., 2000) indicate that MAT rose from a low of $\sim 11$ to $\sim 16^{\circ} \mathrm{C}$ around the time of faunal event B-2. Although the rate of this temperature increase is unknown, there is no evidence of a CIE in the McCullough Peaks isotope sections of Abels et al. (2012) to suggest a hyperthermal mechanism at Biohorizon B. Coincident lithological changes, such as increased sediment accumulation rate and common channel sandstones and mudfilled scours, may reflect tectonic activity on the southern edge of the basin (Bown and Kraus, 1993) and/or marked increases in temperature, precipitation and/or seasonality of precipitation (as in Foreman, 2014; Foreman et al., 2012). At the same time, floras began to transition to subtropical and tropical species (Wilf, 2000; Wing et al., 2000), indicating the possible development of a canopy that would account for coincident changes in soil moisture (Bown and Kraus, 1993) and temperature (Snell et al., 2013). Biohorizon B, the largest faunal event in the FC record after the PETM, coincides with the onset of this warming and related lithological and floral change and marks a major turning point in faunal diversity that has been correlated with jumps in generic alpha richness and turnover across North America (Chew and Oheim, 2013; Woodburne et al., 2009). In the FC record, Biohorizon $\mathrm{B}$ is distinguished by a burst of new species that were not immigrants, heralding long-term increases in alpha richness and evenness (Fig. 4; Chew and Oheim, 2013). There is also a proliferation of body sizes at this time, although abundance shifts tend to favor relatively smaller species (Fig. 5; Bown et al., 1994a). These results support the interpretation of Woodburne et al. (2009) that there was major evolutionary innovation in the lead-up to the EECO. 
Table 2. Comparison of faunal change at the PETM and faunal events B-1 and B-2. Summary paleoecological parameter values are calculated for the entire PETM sample (Rose et al., 2012) and the entire faunal event B-1 and B-2 samples. Proportions of taxa lost at the PETM are based on the Clarkforkian (late Paleocene) Bighorn Basin mammal fauna described in Rose (1981). Proportions of change in body size at the PETM are from Secord et al. (2012). Proportions of change in body size at faunal events B-1 and B-2 are based on the total number of taxa for which body size can be assessed.

\begin{tabular}{|c|c|c|c|c|c|}
\hline Parameter & & PETM & B-1 & B-2 & Biohorizon B \\
\hline \multicolumn{6}{|l|}{ Diversity } \\
\hline & Proportion of alpha richness & $29: 39$ & $24: 39$ & $23: 39$ & $26: 34$ \\
\hline & Proportion of beta richness & $10: 39$ & $15: 39$ & $16: 39$ & $8: 34$ \\
\hline & Proportion of evenness (inclusive abundance) & $0.92: 1.84$ & $0.92: 1.8$ & $0.91: 1.78$ & $0.92: 1.78$ \\
\hline & Proportion of dominance (inverse dominance) & $0.92: 1.84$ & $0.88: 1.8$ & $0.87: 1.78$ & $0.86: 1.78$ \\
\hline \multicolumn{6}{|l|}{ Turnover } \\
\hline & Proportion of new species & $46: 58$ & $14: 78$ & $6: 77$ & $13: 70$ \\
\hline & Proportion of new genera & $20: 42$ & $3: 53$ & $2: 53$ & $8: 51$ \\
\hline & Proportion of species lost & $18: 39$ & $12: 78$ & $6: 77$ & $70: 70$ \\
\hline & Proportion of genera lost & $7: 39$ & $2: 53$ & $1: 53$ & $3: 51$ \\
\hline \multicolumn{6}{|l|}{ Body size } \\
\hline & Proportion of genera in which body size decreases & $10: 26$ & $6: 35$ & $2: 35$ & $6: 32$ \\
\hline & Proportion of genera in which body size increases & $0: 26$ & $7: 35$ & $9: 35$ & $4: 32$ \\
\hline
\end{tabular}

Faunal events B-1 and B-2 are distinct intervals of change set within the context of Biohorizon B. Abundance, evenness, dominance and body size trends were initiated at, or before, Biohorizon B (e.g., some long-term increases in size and the relative abundance of dominant species; see Chew, 2009a, b; Chew and Oheim, 2013) and carried through faunal events B-1 and B-2. However, faunal events B-1 and B-2 are unique in their higher proportions of species loss, which nearly equal the proportions of new species at each event (Table 2). Nearly half of the turnover at faunal events B-1 and B-2 occurs within lineages, with correspondingly small proportions $(\leq 6 \%)$ of generic events. In contrast, and in spite of their widely different mechanisms, both the PETM and Biohorizon B are characterized by bursts of new species, including many new genera, and comparatively few losses. The PETM was a transient episode of ecological change, including immigration and body size adjustment, whereas Biohorizon B involved marked evolutionary change in this basin (Chew and Oheim, 2013). Both events were initiated by significant climatic and environmental disturbance that ended $\geq 1 \mathrm{Myr}$ periods of relatively static conditions: warm and moist before the PETM and cool and dry before Biohorizon B (Kraus et al., 2013; Kraus and Riggins, 2007; Snell et al., 2013; Wilf, 2000; Wing et al., 2000). In contrast, the CIEs indicating the rapid warming of ETM2 and H2 occurred soon after the onset of the climatic and environmental disturbance at Biohorizon B in the lead-up to the EECO. Faunal structure may have been comparatively unstable as communities were adjusting to changing conditions, perhaps leaving more species vulnerable to further change. The turnover within lineages at faunal events B-1 and B-2 suggests that more species were lost through evolutionary transitions at this time.
Faunal events B-1 and B-2 are also unique in their high proportions of beta richness (Table 2). Beta richness reflects heterogeneity in species incidence patterns (Collins and Simberloff, 2009; Colwell et al., 2004; Gotelli and Colwell, 2001) that may occur through specialization for dispersed microhabitats and/or heightened ecological interactions that prompt species to seek out or avoid each other (e.g., competition, predation). Previous analysis identified a rise in beta richness in the $\sim 2 \mathrm{Myr}$ after Biohorizon $\mathrm{B}$ to which both mechanisms may have contributed (Fig. 3; Chew and Oheim, 2013; Woodburne et al., 2009). A coincident longterm increase in alpha richness (Fig. 3; Chew and Oheim, 2013; Woodburne et al., 2009) implies that there were more species packed into the available space of the landscape, increasing the potential for ecological interactions. Increased habitat complexity as subtropical and tropical floras became more established implies more opportunities for microhabitat specialization (Chew and Oheim, 2013; Wing et al., 2000; Woodburne et al., 2009). The proportions of new species and alpha richness are not particularly high at faunal events B-1 and B-2, suggesting that the temporary peaks in beta richness at ETM2 and $\mathrm{H} 2$ are probably not related to an acceleration of species packing and heightened ecological interactions. Instead, they may represent increased microhabitat specialization in response to transient increases in floral complexity, perhaps heightened by the more seasonal, possibly more intense and episodic, precipitation suggested by transient lithological changes (Abels et al., 2012).

\section{Summary}

This analysis highlights the importance of analytical resolution and the use of multiple parameters in the paleoecological 
analysis of whole communities. Two previously unsuspected episodes of faunal change potentially related to the ETM2 and $\mathrm{H} 2$ hyperthermals are identified. A comparison of diverse and complementary lines of evidence summarizing different functional and ecological groups allows the differentiation of superficially similar faunal responses at faunal events B-1 and B-2 and the PETM. Faunal change at the PETM is characterized by pronounced turnover fueled by immigration and widespread decreases in body size. These changes are probably related to the combination of rapid warming and drying at the PETM. In contrast, faunal change at faunal events B-1 and B-2 is less extreme, is not fueled by immigration, and involves a proliferation of body sizes, although abundance shifts tend to favor smaller sizes. Faunal events B1 and B-2 are set in the context of pronounced climatic, environmental and faunal change related to warming in the leadup to the EECO. Faunal events B-1 and B-2 are distinctive in their high proportions of species losses potentially related to heightened species vulnerability in response to the changes already underway in the run-up to the EECO. Faunal events B-1 and B-2 are also distinctive in that they show high proportions of beta richness, suggestive of increased geographic dispersal related to transient increases in habitat (floral) complexity and/or precipitation or seasonality of precipitation.

\section{The Supplement related to this article is available online at doi:10.5194/cp-11-1223-2015-supplement.}

Acknowledgements. This project was supported by the National Science Foundation Sedimentary Geology and Paleobiology program grants 0739718 and 0616430 , and in part by the National Geographic Society Waitt Program grant W315-14. The author gratefully acknowledges the substantial efforts of K. Rose and students and volunteers who have collected, curated and catalogued the specimens on which the research is based. The collections are housed at the Smithsonian National Museum of Natural History. Rarefaction software was downloaded from the University of Georgia Stratigraphy Lab webpage of S. Holland (http://www.uga.edu/ strata/software/Software.html) and from the University of Connecticut Ecology and Evolutionary Biology webpage of R. Colwell (http://viceroy.eeb.uconn.edu/EstimateS/). $\mathrm{R}$. Chew wrote the algorithm to standardize species appearance data.

Edited by: G. Dickens

\section{References}

Abels, H. A., Clyde, W. C., Gingerich, P. D., Hilgen, F. J., Fricke, H. C., Bowen, G. J., and Lourens, L. J.: Terrestrial carbon isotope excursions and biotic change during Paleogene hyperthermals, Nature Geosci., 5, 326-329, 2012.
Alroy, J.: New methods for quantifying macroevolutionary patterns and processes, Paleobiology, 26, 707-733, 2000.

Bao, H., Koch, P. L., and Rumble, D.: Paleocene-Eocene climatic variation in western North America: evidence from the delta ${ }^{18} \mathrm{O}$ of pedogenic hematite, Geol. Soc. Am. Bull., 111, 1405-1415, 1999.

Bowen, G. J., Clyde, W. C., Koch, P. L., Ting, S., Alroy, J., Tsubamoto, T., Wang, Y., and Wang, Y.: Mammalian dispersal at the Paleocene/Eocene boundary, Science, 295, 2062-2065, 2002.

Bowen, G. J., Bralower, T. J., Delaney, M. L., Dickens, G. R., Kelley, D. C., Koch, P. L., Kump, L. R., Meng, J., Sloan, L. C., Thomas, E., Wing, S. L., and Zachos, J. C.: Eocene hyperthermal event offers insight into greenhouse warming, EOS (Transactions, American Geophysical Union), 87, 165-169, 2006.

Bown, T. M. and Kraus, M. J.: Time-stratigraphic reconstruction and integration of paleopedologic, sedimentologic, and biotic events (Willwood Formation, Lower Eocene, northwest Wyoming, USA), Palaios, 8, 68-80, 1993.

Bown, T. M., Holroyd, P. A., and Rose, K. D.: Mammal extinctions, body size, and paleotemperature, P. Nat. Acad. Sci. USA, 93, 1705-1709, 1994a.

Bown, T. M., Rose, K. D., Simons, E. L., and Wing, S. L.: Distribution and Stratigraphic Correlation of Upper Paleocene and Lower Eocene Fossil Mammal and Plant Localities of the Fort Union, Willwood, and Tatman Formations, Southern Bighorn Basin, Wyoming, USGS Professional Paper 1540, Denver, 1994b.

Burger, B. J.: Northward range extension of a diminutivesized mammal (Ectocion parvus) and the implication of body size change during the Paleocene-Eocene Thermal Maximum, Palaeogeogr. Palaeocl., 363, 144-150, 2012.

Caron, J. B. and Jackson, D. A.: Paleoecology of the Greater Phyllopod Bed community, Burgess Shale: Palaeogeogr. Palaeocl., 258, 222-256, 2008.

Chen, I. C., Hill, J. K., Ohlemuller, R., Roy, D. B., and Thomas, C. D.: Rapid range shifts of species associated with high levels of climate warming, Science, 333, 1024-1026, 2011.

Chew, A. E.: Paleoecology of the early Eocene Willwood mammal fauna from the central Bighorn Basin, Wyoming, Paleobiology, 359, 13-31, 2009a.

Chew, A. E.: Early Eocene mammal faunal response to temperature change in the Bighorn Basin, WY, in: Climatic and Biotic Events of the Paleogene (CBEP 2009), GNS Science Miscellaneous Series 18 , Wellington, NZ, 21-25, 2009b.

Chew, A. E. and Oheim, K. B.: The use of GIS to determine the effects of common taphonomic biases on paleoecological statistics of vertebrate fossil assemblages, Palaios, 24, 367-376, 2009.

Chew, A. E. and Oheim, K. B.: Diversity and climate change in the middle-late Wasatchian (early Eocene) Willwood Formation, central Bighorn Basin, Wyoming, Palaeogeogr. Palaeocl., 369, 67-78, 2013.

Chiarucci, A., Bacaro, G., Rocchini, D., and Fattorini, L.: Discovering and rediscovering the sample-based rarefaction formula in the ecological literature, Community Ecol., 9, 121-123, 2008.

Clementz, M., Bajpai, S., Ravikant, V., Thewissen, J. G. M., Saravanan, N., Singh, I. B., and Prasad, V.: Early Eocene warming events and the timing of terrestrial faunal exchange between India and Asia, Geology, 39, 15-18, 2011.

Clyde, W. C. and Gingerich, P. D.: Mammalian community response to the latest Paleocene thermal maximum: an isotapho- 
nomic study in the northern Bighorn Basin, Wyoming, Geology, 26, 1011-1014, 1998.

Clyde, W. C., Hamzi, W., Finarelli, J. A., Wing, S. L., Schankler, D., and Chew, A.: Basin-wide magneto stratigraphic framework for the bighorn basin, Wyoming, Geol. Soc. Am. Bull., 119, 848$859,2007$.

Collins, M. D. and Simberloff, D.: Rarefaction and nonrandom spatial dispersion patterns, Environ. Ecol. Stat., 16, 89-103, 2009.

Collinson, M. E., Hooker, J. J., and Grocke, D. R.: Cobham lignite bed and penecontemporaneous macrofloras of southern England: a record of vegetation and fire across the Paleocene-Eocene Thermal Maximum, in: Causes and Consequences of Globally Warm Climates in the Early Paleogene, edited by: Wing, S. L., Gingerich, P. D., Schmidtz, B., and Thomas, E., Geol. Soc. Am. Special Paper 369, Boulder, CO, 333-350, 2003.

Colwell, R. K.: EstimateS 9.1: Statistical Estimation of Species Richness and Shared Species from Samples (Software and User's Guide), http://purl.oclc.org/estimates, 2013.

Colwell, R. K., Mao, C. X., and Chang, J.: Interpolating, extrapolating, and comparing incidence-based species accumulation curves, Ecology, 85(10), 2717-2727, 2004.

Cramer, B. S., Wright, J. D., Kent, D. V., and Aubry, M.-P.: Orbital climate forcing of delta ${ }^{13} \mathrm{C}$ excursions in the late Paleoceneearly Eocene (chrons C24n-C25n), Paleoceanography, 18, 1097, doi:10.1029/2003PA000909, 2003.

Crist, T. O. and Veech, J. A.: Additive partitioning of rarefaction curves and species-area relationships: unifying alpha-, beta- and gamma diversity with sample size and habitat area, Ecol. Lett., 9, 923-932, 2006.

Currano, E. D., Wilf, P., Wing, S. L., Labandeira, C. C., Lovelock, E. C., and Royer, D. L.: Sharply increased insect herbivory during the Paleocene-Eocene thermal maximum, P. Nat. Acad. Sci. USA, 105, 1960-1964, 2008.

D'Ambrosia, A. R., Clyde, W. C., Fricke, H. C., and Gingerich, P. D.: Repetitive mammalian dwarfism associated with early Eocene carbon cycle perturbations, Rend. Online Soc. Geol. It., 31, 52-53, 2014.

Foden, W., Midgley, G. F., Hughes, G., Bond, W. J., Thuiller, W., Hoffman, M. T., Kaleme, P., Underhill, L. G., Rebelo, A., and Hannah, L.: A changing climate is eroding the geographical range of the Namib Desert tree Aloe through population declines and dispersal lags, Diversity and Distributions, 13, 645653, 2007

Foote, M.: Rarefaction analysis of morphological and taxonomic diversity, Paleobiology, 18, 1-16, 1992.

Foote, M.: Origination and extinction components of taxonomic diversity: general problems, Paleobiology, 26 (Supplement to no. 4), 74-102, 2000.

Foreman, B. Z.: Climate-driven generation of a fluvial sheet sand body at the Paleocene-Eocene boundary in north-west Wyoming (USA), Basin Res., 26, 225-241, 2014.

Foreman, B. Z., Heller, P. L., and Clementz, M. T.: Fluvial response to abrupt global warming at the Palaeocene/Eocene boundary, Nature, 491, 92-95, 2012.

Foster, L. C., Schmidt, D. N., Thomas, E., Arndt, S., and Ridgwell, A.: Surviving rapid climate change in the deep sea during the Paleogene hyperthermals, P. Nat. Acad. Sci. USA, 110, 92739276, 2013
Fricke, H. C. and Wing, S. L.: Oxygen isotope and paleobotanical estimates of temperature and delta(18) O-latitude gradients over North America during the Early Eocene: Am. J. Sci., 304, 612635, 2004.

Gibbs, S. J., Bown, P. R., Murphy, B. H., Sluijs, A., Edgar, K. M., Pälike, H., Bolton, C. T., and Zachos, J. C.: Scaled biotic disruption during early Eocene global warming events, Biogeosciences, 9, 4679-4688, doi:10.5194/bg-9-4679-2012, 2012.

Gingerich, P. D.: New earliest Wasatchian mammalian fauna from the Eocene of Northwestern Wyoming: composition and diversity in a rarely sampled high-floodplain assemblage, University of Michigan Papers on Paleontology, Ann Arbor, Michigan, 1989.

Gingerich, P. D.: Biostratigraphy of the continental PaleoceneEocene boundary interval on Polecat bench in the northern Bighorn Basin, in: Paleocene-Eocene stratigraphy and biotic change in the Bighorn and Clarks Fork Basins, Wyoming, edited by: Gingerich, P. D., University of Michigan Papers on Paleontology Volume 33, Ann Arbor, Michigan, 37-71, 2001.

Gingerich, P. D.: Environment and evolution through the PaleoceneEocene Thermal Maximum, Trends Ecol. Evol., 21, 246-253, 2006.

Gingerich, P. D. and Smith, T.: Paleocene-Eocene land mammals from three new latest Clarkforkian and earliest Wasatchian wash sites at Polecat Bench in the northern Bighorn Basin, Wyoming, Contributions from the Museum of Paleontology, University of Michigan, 31, 245-303, 2006.

Gotelli, N. J. and Colwell, R. K.: Quantifying biodiversity: procedures and pitfalls in the measurement and comparison of species richness, Ecol. Lett., 4, 379-391, 2001.

Holland, S.: Analytic Rarefaction 1.3 (Software and User's Guide), University of Georgia, Athens, GA, 2003.

Hurlburt, S. H.: The nonconcept of species diversity: a critique and alternative parameters, Ecology, 52, 577-586, 1971.

Koch, P. L., Clyde, W. C., Hepple, R. P., Fogel, M. L., Wing, S. L., and Zachos, J. C.: Carbon and oxygen isotope records from paleosols spanning the Paleocene-Eocene boundary, Bighorn Basin, Wyoming, in: Causes and Consequences of Globally Warm Climates in the Early Paleogene, edited by: Wing, S. L., Gingerich, P. D., Schmidtz, B., and Thomas, E., Geol. Soc. Am. Special Paper 369, Boulder, CO, 49-64, 2003.

Kraus, M. J. and Riggins, S.: Transient drying during the PaleoceneEocene Thermal Maximum (PETM): Analysis of paleosols in the Bighorn Basin, Wyoming, Palaeogeogr. Palaeocl., 245, 444-461, 2007.

Kraus, M. J., McInerney, F. A., Wing, S. L., Secord, R., Baczynski, A. A., and Bloch, J. I.: Paleohydrologic response to continental warming during the Paleocene-Eocene Thermal Maximum, Bighorn Basin, Wyoming, Palaeogeogr. Palaeocl., 370, 196-208, 2013.

Lourens, L. J., Sluijs, A., Kroon, D., Zachos, J. C., Thomas, E., Rohl, U., Bowles, J., and Raffi, I.: Astronomical pacing of late Palaeocene to early Eocene global warming events, Nature, 435, 1083-1087, 2005.

Luterbacher, H., Hardenbol, J., and Schmitz, B.: Decision of the voting members of the International Subcommission on Paleogene Stratigraphy on the criterion for the recognition of the Paleocene/Eocene boundary, Newsl. Int. Subcomm. Paleogene Stratigr., 9, 13 pp., 2000. 
Magurran, A. E.: Measuring Biological Diversity, Wiley-Blackwell, Indianapolis, IN, 2004.

McInerney, F. A. and Wing, S. L.: The Paleocene-Eocene Thermal Maximum: a perturbation of carbon cycle, climate, and biosphere with implications for the future, Annu. Rev. Earth Pl. Sc., 39, 489-516, 2011.

Nicolo, M., Dickens, G. R., Hollis, C. J., and Zachos, J. C.: Multiple early Eocene hyperthermals: their sedimentary expression on the New Zealand continental margin and in the deep sea, Geology, 35, 699-702, 2007.

Olszewski, T. D.: A unified mathematical framework for the measurement of richness and evenness within and among multiple communities, Oikos, 104, 377-387, 2004.

Rose, K. D., Chester, S. G. B., Dunn, R. H., Boyer, D. M., and Bloch, J. I.: New Fossils of the Oldest North American Euprimate Teilhardina brandti (Omomyidae) from the PaleoceneEocene Thermal Maximum, Am. J. Phys. Anthropol., 146, 281305, 2011.

Rose, K. D., Chew, A. E., Dunn, R. H., Kraus, M. J., Fricke, H. C., and Zack, S. P.: Earliest Eocene mammalian fauna from the Paleocene-Eocene Thermal Maximum at Sand Creek Divide, southern Bighorn Basin, Wyoming, University of Michigan Papers on Paleontology Volume 36, Ann Arbor, Michigan, 2012.

Samanta, A., Bera, M. K., Ghosh, R., Bera, S., Filley, T., Pande, K., Rathore, S. S., Rai, J., and Sarkar, A.: Do the large carbon isotopic excursions in terrestrial organic matter across PaleoceneEocene boundary in India indicate intensification of tropical precipitation?, Palaeogeogr. Palaeocl., 387, 91-103, 2013.

Sanders, H. L.: Marine benthic diversity: a comparative study, Am. Nat., 102, 243-282, 1968.

Schankler, D.: Faunal zonation of the Willwood Formation in the central Bighorn Basin, Wyoming, in: Early Cenozoic Paleontology and Stratigraphy of the Bighorn Basin, Wyoming, edited by: Gingerich, P. D., University of Michigan Papers on Paleontology Volume 24, Ann Arbor, Michigan, 99-114, 1980.

Secord, R., Gingerich, P. D., Lohmann, K. C., and MacLeod, K. G.: Continental warming preceding the Palaeocene-Eocene thermal maximum, Nature, 467, 955-958, 2010.

Secord, R., Bloch, J. I., Chester, S. G. B., Boyer, D. M., Wood, A. R., Wing, S. L., Kraus, M. J., McInerney, F. A., and Krigbaum, J.: Evolution of the earliest horses driven by climate change in the Paleocene-Eocene Thermal Maximum, Science 335, 959-962, 2012.

Sexton, P. F., Norris, R. D., Wilson, P. A., Palike, H., Westerhold, T., Rohl, U., Bolton, C. T., and Gibbs, S.: Eocene global warming events driven by ventilation of oceanic dissolved organic carbon, Nature, 471, 349-353, 2011.

Sheridan, J. A. and Bickford, D.: Shrinking body size as an ecological response to climate change, Nature Climate Change, 1, 401-406, 2011.

Silcox, M. T., Rose, K. D., and Chew, A.: Early Eocene microsyopine microsyopids (Mammalia, Primates) from the southern Bighorn Basin, Wyoming: evidence for cladogenetic speciation and evolutionary response to climate change, J. Vertebr. Paleontol. Abstracts, 74th Annual Meeting, 230, 2014.

Sluijs, A., Schouten, S., Donders, T. H., Schoon, P. L., Rohl, U., Reichart, G.-J., Sangiorgi, F., Kim, J.-H., Sinninghe Damste, J. S., and Brinkhuis, H.: Warm and wet conditions in the Arctic region during Eocene Thermal Maximum 2, Nature Geosci., 2, 777-780, 2009.

Smith, J. J., Hasiotis, S. T., Kraus, M. J., and Woody, D. T.: Transient dwarfism of soil fauna during the Paleocene-Eocene Thermal Maximum, P. Nat. Acad. Sci. USA, 106, 17655-17660, 2009.

Smith, M. E., Singer, B., and Carroll, A.: ${ }^{40} \mathrm{Ar} /{ }^{39} \mathrm{Ar}$ geochronology of the Eocene Green River Formation, Wyoming: Reply, Geol. Soc. Am. Bull., 116, 253-256, 2004.

Snell, K. E., Thrasher, B. L., Eiler, J. M., Koch, P. L., Sloan, L. C., and Tabor, N. J.: Hot summers in the Bighorn Basin during the early Paleogene, Geology, 41, 55-58, 2013.

Snell, K. E., Fricke, H. C., Clyde, W. C., and Eiler, J. M.: Large temperature changes on land during Early Eocene hyperthermals, Rend. Online Soc. Geol. It., 31, 204-205, 2014.

Stap, L., Lourens, L. J., Thomas, E., Sluijs, A., Bohaty, S., and Zachos, J. C.: High-resolution deep-sea carbon and oxygen isotope records of Eocene Thermal Maximum 2 and H2, Geology, 38, 607-610, 2010.

Stassen, P., Steurbaut, E., Morsi, A. M. M., Schulte, P., and Speijer, R. P.: Biotic impact of Eocene Thermal Maximum 2 in a shelf setting (Dababiya, Egypt), Austrian Journal of Earth Sciences, 105, 154-160, 2012.

Tsukui, K. and Clyde, W. C.: Fine-tuning the calibration of the early to middle Eocene geomagnetic polarity time scale: Paleomagnetism of radioisotopically dated tuffs from Laramide foreland basins, Geol. Soc. Am. Bull., 124, 870-885, 2012.

VanDeVelde, J. H., Bowen, G. J., Passey, B. H., and Bowen, B. B.: Climatic and diagenetic signals in the stable isotope geochemistry of dolomitic paleosols spanning the Paleocene-Eocene boundary, Geochim. Cosmochim. Ac., 109, 254-267, 2013.

Wilf, P.: Late Paleocene-early Eocene climatic changes in southwestern Wyoming: Paleobotanical analysis, Geol. Soc. Am. Bull., 112, 292-307, 2000.

Wing, S. L., Bown, T. M., and Obradovich, J. D.: Early Eocene biotic and climatic change in interior western North America, Geology, 9, 1189-1192, 1991.

Wing, S. L., Bao, H., and Koch, P. L.: An early Eocene cool period? Evidence for continental cooling during the warmest part of the Cenozoic, in: Warm Climates in Earth History, edited by: Huber, B. T., MacLeod, K. G., and Wing, S. L., Cambridge University Press, Cambridge, 197-237, 2000.

Wing, S. L., Harrington, G. J., Smith, F. A., Bloch, J. I., Boyer, D. M., and Freeman, K. H.: Transient floral change and rapid global warming at the Paleocene-Eocene boundary, Science, 310, 993 996, 2005.

Wood, H. E.: Nomenclature and correlation of the North American continental Tertiary, Bull. Geol. Soc. Am., 52, 1-48, 1941.

Woodburne, M. O., Gunnell, G. F., and Stucky, R. K.: Climate directly influences Eocene mammal faunal dynamics in North America, P. Nat. Acad. Sci., 106, 13399-13403, 2009.

Yans, J., Strait, S. G., Smith, T., Dupuis, C., Steurbaut, E., and Gingerich, P. D.: High-resolution carbon isotope stratigraphy and mammalian faunal change at the Paleocene-Eocene boundary in the Honeycombs area of the southern Bighorn Basin, Wyoming, Am. J. Sci., 306, 712-735, 2006.

Zachos, J. C., Pagani, M., Sloan, L., Thomas, E., and Billups, K.: Trends, rhythms, and aberrations in global climate 65 Ma to present, Science, 292, 686-693, 2001. 
Zachos, J. C., Rohl, U., Schellenberg, S. A., Sluijs, A., Hodell, D. A., Kelly, D. C., Thomas, E., Nicolo, M., Raffi, I., Lourens, L. J., McCarren, H., and Kroon, D.: Rapid acidification of the ocean during the Paleocene-Eocene thermal maximum, Science, 308, 1611-1615, 2005.
Zachos, J. C., Dickens, G. R., and Zeebe, R. E.: An early Cenozoic perspective on greenhouse warming and carbon-cycle dynamics, Nature, 451, 279-283, 2008. 